\title{
Science- and Engineering-Related Ethics and Values Studies: Characteristics of an Emerging Field of Research
}

\author{
Rachelle D. Hollander \\ National Science Foundation \\ Nicholas H. Steneck \\ University of Michigan
}

During the past decade, studies of ethical and value aspects of the interactions between science, technology, and society have begun to develop as a research area. The intellectual impetus behind this development is clear. As with all human endeavors, science and engineering involve management, and managing human endeavors requires making decisions with implications for human values and norms. The objective of this article is to describe and comment on the characteristics of this emerging research field. The main source of evidence is proposals funded since the mid-1970s by Ethics and Values Studies (EVS; formerly Ethics and Values in Science and Technology - EVIST) at the National Science Foundation.

\section{Origin and Growth}

The social origins and growth of science- and engineering-related ethics and values (SEEV) studies are closely linked to the larger "science, technology, and society" or "STS" movement in the United States (Cutcliffe 1989). Beginning in the mid-1960s, U.S. colleges and universities began to respond to their campuses' growing social awareness by establishing STS programs.

\footnotetext{
AUTHORS' NOTE: The opinons in this article are the authors' own and do not reflect opinons of the National Science Foundation.
} 
The goals of most of the early programs were education and consciousness raising. The war in Vietnam and growing concern over the environment led many academicians to conclude that they and their universities had obligations to examine and inform others about the social dimensions of scientific and technological development. Included in this sense of obligation, particularly at the National Science Foundation, was special concern for ethics and values (EV) (Fusfield 1974).

As the STS movement grew in the 1970s, signs of institutionalization began to appear. New journals, such as Science, Technology, \& Human Values, were started. Older, established science and technology journals, such as Technology and Culture, devoted more space to social concerns (Blanpied 1982, 6-7; Staudenmaier 1985, 1-34). NSF's EVIST Program and its counterpart in the National Endowment for the Humanities began funding EV and STS research in 1975. Professional societies devoted more attention to social issues. One important new professional society, the Society for Social Studies of Science (4S), was formed. Simultaneously, the number of STS programs increased dramatically, numbering over 100 in a survey by the American Association for the Advancement of Science (AAAS) published in 1978 (AAAS 1978; see also Heitowit, Epstein, and Steinberg 1976, Roy and Lerner 1983).

The 1980s have added more signs of institutionalization. The STS community is now large enough and well enough organized to form special sections in professional associations, such as the Section on Science, Knowledge, and Technology of the American Sociological Association or Section X of the AAAS: Societal Impacts of Science and Engineering. STS scholars also hold special sessions at major national meetings or sponsor independent STS meetings. A 1987 STS conference held at Worcester Polytechnic Institute in conjunction with an annual $4 \mathrm{~S}$ meeting drew participants from Australia, most major European countries, and approximately 30 programs in the United States (Conference on the State of Science, Technology, and Society Programs 1987). Penn State has sponsored an annual "scientific literacy" conference since 1976, from which has developed the National Association for Science, Technology, and Society.

These developments provide evidence that SEEV activities are becoming institutionalized. A large community of teachers and researchers identify themselves either mostly or in part as STS professionals. Professional societies exist for these individuals to join and a number of journals serve as outlets for their professional activities. An evolving literature seeks to study and comment on the growing professionalization of SEEV and STS activities (Adams, Durbin, and Hollander 1986). 
Table 1. Number of Projects Funded Yearly by NSF-EVIST/EVS $\mathrm{N}=172$

\begin{tabular}{cc} 
Year & Number of Projects \\
\hline 1976 & 23 \\
1977 & 12 \\
1978 & 17 \\
1979 & 14 \\
1980 & 10 \\
1981 & 17 \\
1982 & 11 \\
1983 & 8 \\
1984 & 14 \\
1985 & 15 \\
1986 & 10 \\
1987 & 21 \\
\hline
\end{tabular}

However, to accept institutionalization as evidence for professionalization raises a significant problem. Scholars generally define "professions" in terms that include more than external forms or institutions. Sociologist Andrew Abbott, for example, adds skills and knowledge to his definition, arguing that a profession is "an exclusive occupational group possessing a specialized skill that is based in some way on esoteric knowledge" (Abbott $1983,856)$. If professionalization requires more than establishing professional organizations, then, in judging the development of SEEV or STS activities, it is important to ask whether there are fundamental ingredients that bind this area of study together as a field of research. This article argues that such ingredients are at present not well enough defined to conclude that a new profession has emerged, and makes several recommendations in the hopes of strengthening the intellectual and institutional dimensions of what is now primarily an area of study.

\section{NSF, EVIST/EVS Projects: Basic Characteristics}

The National Science Foundation began funding EV research on a regular basis in 1975. Thereafter, on average about 15 SEEV projects have been funded each year (Table 1). The Foundation's criteria for support have been general and inclusive. ${ }^{1}$ To qualify, projects study ethical or values issues relating to scientific or technological developments. Interdisciplinary or collaborative research is encouraged. Relevance, applicability, and accep- 
Table 2. EVS Projects Grouped by Areas of Interest $N=172$

\begin{tabular}{lrrrrrrrrrrrrr}
\hline Year & 76 & 77 & 78 & 79 & 80 & 81 & 82 & 83 & 84 & 85 & 86 & 87 & Totals \\
\hline Agricultural Ethics & - & 1 & 1 & - & - & - & 1 & 2 & - & 1 & 1 & 1 & 8 \\
Animal Use & - & - & - & - & - & 1 & - & - & 1 & - & 1 & 2 & 5 \\
Risk/Benefit Analysis & - & 2 & 1 & - & - & 1 & - & - & 1 & 1 & - & 3 & 9 \\
Computers & 2 & - & - & - & 1 & - & 2 & - & 2 & - & 1 & 1 & 9 \\
Discrimination & 1 & - & - & - & - & 1 & - & - & - & 1 & - & - & 3 \\
RDNA/Genetics & 1 & - & 1 & - & - & 2 & - & - & - & 2 & - & 2 & 8 \\
Engineering Ethics & 1 & - & 3 & 2 & 2 & 2 & 1 & - & - & 1 & 1 & 2 & 15 \\
Environmental Issues & 5 & 1 & 1 & 1 & - & 1 & 1 & 1 & 2 & - & 1 & 1 & 15 \\
Hazards & 2 & 1 & 2 & - & 3 & 5 & 3 & 2 & 2 & 3 & 1 & 1 & 25 \\
University-Industrial Rel. & - & - & - & - & - & - & - & 1 & 1 & 1 & 1 & 1 & 5 \\
Medical Ethics & 2 & 2 & 3 & 3 & 4 & 1 & 1 & - & 3 & 1 & - & - & 20 \\
Energy & - & 1 & - & 2 & - & - & - & 1 & - & - & - & - & 4 \\
Publication Ethics & - & - & - & - & - & - & - & - & - & 1 & 1 & 1 & 3 \\
Education & 3 & 1 & 1 & 4 & - & 2 & 1 & 1 & - & 2 & 1 & 5 & 21 \\
Social Sciences & 2 & 1 & 2 & 1 & - & - & 1 & - & 1 & 1 & - & - & 9 \\
STS & 4 & 2 & 2 & 1 & - & 1 & - & - & 1 & - & 1 & 1 & 13 \\
Totals & 23 & 12 & 17 & 14 & 10 & 17 & 11 & 8 & 14 & 15 & 10 & 21 & 172 \\
\hline
\end{tabular}

tance by peers are important. Beyond these general criteria, researchers have been free to propose projects to the Foundation. Thus the proposals submitted are a reasonable source for studying the emerging field of SEEV research.

Project characteristics. Few aspects of human life today are untouched by scientific and technological development. Diversity is therefore the most manifest characteristic of the 172 projects that constitute the data base for this article. Problem areas studied range from basic agriculture to high-tech industry, from issues affecting small peer groups to global communities, from the oceans to the land and atmosphere. Researchers from all major academic disciplines have been involved. Projects have used conferences, symposia, historical and contemporary case studies, interviews and questionnaires, surveys, data and content analysis, philosophical and analytical critiques, trend analysis, technology assessment, and most other standard research methodologies. Overall, SEEV studies are as broad and complex as human life itself. 
Despite this spread, a majority of NSF's EVS projects have concentrated on a few important areas (Table 2). Of major interest are topics relating to controversies about the impacts of new technologies on society and about new scientific tools for gauging their impacts. Research on hazards resulted in the largest number (25) of successful proposals (e.g., Fritsch 1976, Kasperson 1977, Mitchell 1978, Baram 1981, Nelkin 1981; EVIST/EVS projects cited in this article in italics are listed in the Appendix). Concern over impacts is the focus of many of the environmental projects (15) and the risk-benefit-related studies (9). In total, these three groups account for 49 projects or $29 \%$ of the total 172 . Moreover, this number certainly underrepresents projects with similar concerns, since many projects in other areas, for example, agricultural, medical, and engineering ethics; recombinant DNA research; and energy-related projects, are also concerned with social impacts (Guttmacher 1979, Westin 1981, Levins 1982).

Two other areas have more than 20 projects: science and engineering education (21) and medical ethics (21). The former has remained a fairly constant concern over the 12 years. Projects in the latter area were more numerous in the beginning and have diminished in importance during the 1980 s, primarily as a result of policy changes in EVIST/EVS. ${ }^{2}$

The decrease in the number of projects relating to medical ethics, along with other time-dependent trends, demonstrates that funding for SEEV research is as dependent on external factors as funding in other areas. New areas of research have emerged in the 1980s in close parallel to the emergence of new areas of controversy. The first animal-use project was funded in 1981, at about the same time that the animal-rights movement was starting to have an impact on government policy (Zola et al. 1984). In the last two years, three more projects have been funded in this area. The first project on universityindustry relations was funded in 1983, roughly the same time that the national debate on this issue was bcginning to heat up (National Science Board 1982, Ashford 1983, Culliton 1983, Deringer and Molnar 1983). The first project on publication ethics was funded in 1985, a year after the appearance of Broad and Wade's controversial Betrayers of the Truth, and at about the same time that a number of professional societies began looking into their publication procedures (Broad and Wade 1982).

It is interesting to note that all three newly emerged research areas - the use of animals in research, university-industry relations, and publication ethics - primarily concern themselves with the practice of science and engineering, as contrasted to areas of longer-standing interest, which focus more on questions of impacts. This trend toward greater concern over the practice 
Table 3. Disciplinary Fields of Pls

\begin{tabular}{lcccc}
\multicolumn{2}{c}{$\mathbf{N}=\mathbf{1 7 2}^{\mathbf{a}}$} & & \\
\hline Area/Discipline & Number/Totals & Area/Discipline & Number/Totals \\
\hline Social Sciences & & 53 & Natural Sciences & 47 \\
Sociology & 19 & Biology & 13 \\
Political Science & 12 & Medicine & 10 \\
Psychology & 7 & Engineering & 7 \\
Economics & 5 & Chemistry & 6 \\
Geography & 5 & Physics & 5 \\
Public Policy & 3 & Earth Science & 2 \\
Anthropology & 1 & Mathematics & 2 \\
Criminology & 1 & Computer Science & 2 \\
Humanities & & Other & 21 \\
Philosophy & 36 & Law & 9 \\
History & 15 & Manag./Operations & 4 \\
& & Communications & 3 \\
& & Environ. Science & 2 \\
& & Architecture & 1 \\
& & Education & 1 \\
\end{tabular}

a. The figures given in this Table are not exact. Some PIs have joint appointments and thus could be listed as representing more than one discipline. Some disciplines could be listed in different areas, for example industrial engineering, which is both engineering and a social science. As a result, it is the trends and not the absolute numbers that are the main focus of this Table.

of science closely parallels increasing demands for societal accountability from science and engineering and is certainly related. Problems surrounding the practice of science and engineering are now fully accepted fields for research alongside the more traditional work on impacts. Whether interest in this area will increase remains to be seen. To be sure, the course of public confidence in science and engineering will play a major role in determining how much this area of research will grow.

PI characteristics. Characteristics of the principal investigators (PIs) provide a second way of describing EVS research. The role PIs play in EVS projects does, of course, vary. Some do all or the majority of the work; others serve more as coordinators for team efforts. So project characteristics are not necessarily the same as PI characteristics. However, PI characteristics do provide insights into the institutional base for SEEV research. Directing proposals requires special commitments that presume institutional encour- 
Table 4. Social Characteristics of PIs $N=176^{a}$

\begin{tabular}{lc} 
& Number \\
\hline Male & 123 \\
Female & 49 \\
Minorities & 3 \\
Handicapped & 1 \\
\hline
\end{tabular}

a. Four projects had co-PIs

Table 5. Sponsoring Organizations of Pls $N=172$

\begin{tabular}{lc}
\hline Institution & Number \\
\hline Postgraduate University & 115 \\
Nonprofit/Public Interest & 26 \\
Professional Society & 19 \\
Undergraduate University & 12 \\
\hline
\end{tabular}

agement and support. Therefore, the characteristics of PIs provide some data about the characteristics of the larger social framework that supports SEEV research.

Not unexpectedly, the majority of EVS PIs have disciplinary bases in the social sciences and humanities (Table 3). Combined, PIs in these two areas directed $61 \%$ (103) of the funded proposals. The division between the two areas is $50 \%-50 \%$ if history is listed with the humanities, and $65 \%$ social sciences, $35 \%$ humanities if history is listed with the social sciences. The most represented discipline is philosophy, which accounts for nearly twice as many proposals (36) as the next most important area, sociology (19). Nearly one-third of EVS projects fall primarily in the natural sciences, with biology and medicine accounting for about half ( 23 of 47 ). ${ }^{3}$

Considered on the basis of race and gender, PIs were more likely to be white $(98 \%)$ and male $(71 \%)$ (Table 4$){ }^{4}$ The latter statistic may change in the future. For the last two granting years, the male/female ratio has been nearly equal ( 16 male, 15 female). However, significant numbers of minority scholars have not been attracted to the field of SEEV research. This situation is problematic, since minorities' perspectives are important in many SEEV projects. Thus bringing more minority scholars into this field of research must remain an important goal, as it is for NSF in general. ${ }^{5}$

Institutionally there are again no surprises. The majority of PIs (67\%) were based in graduate degree-granting universities (Table 5). The remaining 
one-third are spread among nonprofit organizations (15\%; examples are research centers and public-interest organizations), professional societies (11\%), and undergraduate institutions ( $7 \%)$. The low percentage of applications from strictly undergraduate institutions is unexpected, since it is in such institutions that STS teaching programs are the most developed. However, EVS support for projects at undergraduate institutions does resemble the overall distribution in NSF. In 1987, 12\% of NSF research awards went to primarily undergraduate institutions. ${ }^{6}$

\section{Summary}

Overall, SEEV research funded by EVS has interesting, not unexpected characteristics. Typical proposals are submitted by nonminority, male or female social scientists or humanists based at graduate degree-granting academic institutions. The subject matter of their proposals comes from many areas within SEEV studies, with issues of impacts and research practice attracting the most attention.

\section{The World of SEEV Studies}

The primary ingredient that draws these studies together is the desire to do research and provide instruction on the mutual influences between science, engineering, and the moral life of individuals and communities. The particular contexts of relationships that are important to SEEV studiesthose involving values, ethics, and social considerations - are extremely diverse. Studies range from the laboratories of scientific researchers and teachers to local communities where environmental issues are debated. The focus of SEEV investigations can be as narrow as one community of professionals or one event in history; it can be as broad as the entire globe or sweep from past to present and into an indefinite future. Examples from some of the more recent projects funded by NSF EVS serve to illustrate. ${ }^{7}$

Many SEEV projects examine the moral dimensions of science and engineering. James Nelson and Cyprian V. Weaver, a philosopher and a biologist at St. John's University, are examining the ethical implications of the use of animals in diabetes research (Nelson 1987). While the issues under examination have become societal issues, the main objective of the project is to study the way scientists carry out their research. In other words, the focus of the research is on the practice of science and on the moral juncture between scientists and science. 
Similar objectives characterize Paul Portney's work on "Assigning discount rates for future life saving" (Portney 1987). The use of "discount rates" in economics is a common, albeit controversial, practice, particularly when the value of human life is an issue. Portney's project focuses on the way social scientists study personal preferences, which in turn comprise the data on which discount rates are based. To be sure, social concerns provide part of the impetus for this effort. It is also true that, to the extent that this project succeeds, it will have an impact on society. But for the present, this EVS project is focused squarely on SEEV issues associated with the practice of science, in this case, with social science.

Apart from examining science and engineering as traditional intellectual activities, SEEV researchers are interested in the socialization of scientists and engineers. How are they trained? How do their professional organizations function? Are they aware of ethical concerns? Two awards made in 1987 address such questions. Judith Swazey of The Acadia Institute is undertaking an investigation of science and engineering education in an effort to discover if and how professional values and ethical considerations are taught to future scientists and engineers (Swazey 1987). Linda Sweeting, of the Department of Chemistry, Towson State University, received funding for two half-day sessions of the joint meeting of the U.S. and Canadian chemical societies to assess the need to bring ethical issues to the attention of professional chemists and chemistry students (Sweeting 1987). Both projects center on personal and institutional aspects of science and engineering, not their content. Issues relating to society at large provide impetus for both efforts, but they are not the central focus. Questions of professional responsibility and the public interest guide the first investigation. Questions about society's perceptions of professional integrity guide the second.

When and as science and engineering interact with society, new categories of SEEV projects emerge. The most straightforward of these examine ethical implications consequent to new developments in science and technology. Frances M. Lynn, Institute for Environmental Study, University of North Carolina, Chapel Hill, has been funded to help anticipate the impacts of environmental applications of new biotechnologies, a problem that has been the focus of other EVS projects (Lynn 1987; see also Sagoff 1986, Haraway 1987). In such projects, science or engineering is the independent variable; the main concern is its impact on society.

Impacts of science and engineering on moral questions arise from conceptual as well as material developments. Kristin Shrader-Frechette of the Department of Philosophy, University of South Florida, is looking at the 
societal implications of two value-laden concepts used in ecology - balance of nature and community (Shrader-Frechette 1987). Her objective is to understand not only the role these concepts play in ecology but their normative impact on the conclusions ecologists draw from their work and the further normative impact of these conclusions on ecological policy decisions. The causal relationship being studied is the influence science can have on society, not the reverse, with ideas and concepts being the active ingredients. Lynn's study of biotechnology investigates the same causal relationship, but is more concerned with the material impact of new sciences.

As might be expected, SEEV researchers also study the reciprocal dynamic relationship between science or engineering and society, namely, the impact or influence of society on the conduct of science and engineering. One area in which society is having a significant impact on the practice of science is in the use of animals in research. Nelson's project, discussed above, looks at the ethics of the use of animals quite apart from the politics of animal use. An award to Barbara Orlans of the Scientists Center for Animal Welfare brings societal concerns over the use of animals in research to the attention of field biologists and members of institutional animal care committees (Orlans 1987). The award supported a session on new guidelines for nonlaboratory animal care and use, which were generated by four professional societies whose members do research with nondomesticated animals.

Similar interests characterize the work of Deborah Johnson and her colleagues in Science and Technology Studies, Rensselaer Polytechnic Institute, on industry-university research centers (Johnson 1987). They are examining the impacts of new funding arrangements on the practice of science and engineering. These new arrangements have aroused concern about changing the fundamental values of universities and the way research is conducted. Johnson and colleagues are attempting to find out whether this is the case (see also Chalk 1983, Weil 1984, Peters 1986). Their work provides another example of the significant number of projects looking at normative impacts of society on the conduct of science and engineering.

Finally, a significant number of NSF EVS projects examine SEEV issues associated with societal uses of technology, quite apart from the science and engineering that produced these technologies. Norman Daniels, Department of Philosophy, Tufts University, is studying two competing waste treatment technologies from the standpoint of distributive justice and risk assessment (Daniels 1987). His concern is not so much the science and engineering that produced these technologies as the way they are used by society once developed. Does one approach to waste treatment better maximize distribu- 
tive justice? How does each approach deal with risk? How is society using/coping with new technologies and what are the implications of societal response?

\section{Summary}

These examples demonstrate the diversity of SEEV studies, and they illustrate the different interests of scholars who seem to have a common professional bond. They lead to the conclusion that SEEV scholars can be categorized not only by disciplinary affiliations but by the ground they cover within this diverse world. SEEV researchers who are investigating the same field of science or engineering can have little of common interest. One might be interested in the professional or technical aspects of a particular field of science or engineering, another in the relationships between that field and society, or society and that field, and yet another in the way society is coping with products and consequences.

The common denominators that unify SEEV studies are, of course, ethics and values in EVS projects and society in STS studies. However, these common denominators are in many ways too general to provide a common intellectual basis for professional development. Their role might be compared to that of atomic or molecular structure in the physical sciences. All physical scientists in one way or another are concerned with atoms or molecules, but it is no longer this that draws them together. Instead, specific interests within more specialized subdisciplines form the basis for professionalism. Similarly, although there are common bonds that draw SEEV researchers together, it is their specific interests and disciplinary orientations that motivate them professionally, leading to the conclusion that it will be difficult for SEEV research to become a coherent field.

\section{Research Methodologies}

If interests within SEEV research spread broadly across many intellectual areas, aspects of society, and disciplines, it is no surprise that its research methodologies are also diverse. For many researchers, this diversity is problematic. It is usually relatively easy to determine whether a topic is ethics and values-related. It is seldom as easy to determine or explain how that topic can or should be investigated.

The importance of method in research is obvious. Method allows some prediction of likely success. It enables reviewers to understand how a project 
will proceed and to determine whether stated objectives can be achieved. Method legitimates results. Conclusions from a study that uses "appropriate" or "valid" methods are more useful than conclusions from a study that uses vague or unspecified methods. It is as important to know how something is known as it is to know what is known.

Characterized in general terms, most SEEV projects employ one of two familiar approaches to research: (1) individual or collaborative investigations of relevant issues, which often take the form of "case studies"; and (2) group conferences, workshops, and symposia, which enable representatives from different disciplines and constituencies to review the state of knowledge and establish an agenda for research and associated policy recommendations. ${ }^{8}$ Case study or issue-oriented research has the advantage of narrowing the scope of an investigation to manageable proportions, thus getting around the potential problem of the breadth of most SEEV topics. Conferences or symposia are useful because they ensure that varieties of expertise will be brought to bear on a particular problem. Both represent only first steps toward identifying theoretical concerns or defining method; either approach requires further theoretical and methodological refinement.

Case study or issue-oriented research can be undertaken in a number of ways. Some employ principally historical methods. Their main objective is to reconstruct and explain the events surrounding the case or issue in question, using the standard sources for historical research: published materials, manuscript documents, interviews if events are recent enough, other histories, and so on. As with SEEV projects, the primary focus of EVS historical case studies is on the moral dimensions of interactions between science, engineering, and society. Gilbert Wittemore, Jr., an independent investigator in Massachusetts, was funded in 1986 to reconstruct ethical and values issues that influenced the early deliberations of the Federal Radiation Council (Wittemore 1986). His discussion of method described the sources he would use and their likely content. The reliability of this project rested on the reliability of its historical method.

Another approach to case study or issue-oriented investigation uses standard social science research methods. Media and document content analyses, structured and unstructured interviews, participant observation, ethnographic and other anthropological methods, psychological testing, questionnaires, trend analysis, modeling, decision research and analysis, and systems analysis are commonly used in SEEV research. These further refinements in method increase the rigor or exactness of the research in question. Questionnaires, structured interviews, and content analysis yield quantitative data. 
Modeling, ethnographic studies, and psychological testing are established and well-evaluated research methodologies.

A third approach uses humanistically oriented philosophical research techniques to evaluate new developments in science, engineering, or technology. Such techniques rely heavily on analytical and reasoning skills, developed against a background of competing theories, models, ethical systems, and other explanations of human value systems and normative behavior. Philosophical method develops, uses, and evaluates rules for reasoning. Using and assessing these rules to identify and critique the rationales and justifications associated with uses of science and technical method in making decisions about policy and practice is important to SEEV research. Articulating appropriate rules and sound arguments in SEEV projects further strengthens their credibility. Careful identification of rules and premises helps explain how researchers will proceed to define problems, clarify issues, and reach conclusions. It clarifies the critical reasoning skills that underlie a project and gives confidence about the treatment of values and ethics.

Successful issues- or case study-oriented EVS proposals do more than simply name the theoretical orientations and research methods that will be used. They review the relevant literatures, identify important questions, and give sufficient detail to allow reviewers to know that particular methods are being used knowledgeably and properly. They demonstrate familiarity with the strengths and weaknesses of proposed methods. They include brief discussions of the theoretical foundations of the methods being employed and they explain why those methods are appropriate. Such complete discussions establish the basis for judging the validity of projects under review or later when results are published.

Few EVS projects are undertaken by single investigators. More commonly a PI will work closely with one or more colleagues in an interdisciplinary or collaborative team, even when the focus is narrowed to a case study. However, there are times when the team effort itself becomes the basis of a project's research method, as in many conference- or symposium-based projects.

For conference- and symposium-based projects, descriptions of method mainly cover timetables, participant lists, and topics and problems for discussion. It is assumed that scholars with established reputations will participate appropriately when they attend. The purpose of such projects is usually to gather persons with diverse views to assess the state of knowledge in a particular field and to set research agendas for the future. The AAAS 
meeting for which this article was initially prepared, which was planned with EVS support, provides an excellent case (Frankel 1987). ${ }^{9}$ The method used in this "project" was to assemble an appropriate group of scholars to discuss important problems. The project gets its credibility from the scholars included and the list of questions addressed. It is not judged on the basis of specific research methodologies.

Research theory and method are problematic for many would-be SEEV researchers because there is no one appropriate theory or method. Most SEEV projects employ a variety. It is impossible to draw a line between focused case studies and broad team-based conferences and symposia. Symposia can focus on very narrow problems. "Cases" can be very broad. Moreover, there are no convenient formulas for deciding whether historical or social science or philosophic methods are most appropriate for a particular project. Choices must be made, since there are many more appropriate methods than can be used on a single project.

Our experience suggests that it is the explanation of theory and method more than the theories and methods selected that is vitally important to the success of a proposal submitted to EVS. The mere mention of interviews, polls, surveys, literature reviews, philosophical analysis, and so on does not guarantee that a project will be funded. Research can be undertaken effectively or ineffectively. EVS, following the general rule in sponsoring research, will not support projects without evidence that they use appropriate methods in intellectually rigorous ways. We believe, based on many years of reading EVS proposals, that weakness in this area is the single most important factor in explaining why proposals that identify important, researchable topics are not funded.

\section{Conclusions}

A little more than a decade ago, the importance of SEEV research was not recognized in many areas of science and engineering. Although the illusion of value-free science and engineering had been challenged in general in the late 1960s, the understanding that this would have ethical consequences in each area took time to develop. Ethical and values issues had to be clarified, usually field by field. Social issues had to be identified, not in the abstract but as they pertained to specific issues and particular situations. This process began in earnest in the early 1970s, was given a significant boost with the establishment of NSF-EVIST/EVS and its counterpart in NEH, and became 
the essence of SEEV (and STS) research in the late 1970s and early 1980s. Over the past decade, substantial progress has been made.

Along with the progress there have been ongoing problems. Paramount among these is undoubtedly the problem of diversity. SEEV studies are still largely discipline-oriented. The collaboration that has taken place is in many ways superficial. SEEV researchers and teachers are drawn together by an interest in common issues, but their approach to these issues remains tied to existing disciplinary fields. As such, SEEV studies can probably best be characterized as "area studies," in the tradition of other area study programs, such as Afro-American studies, gender studies, European studies, and so on.

The disciplinary organization of SEEV studies has negative consequences. Among other problems, it makes interdisciplinary activity difficult to achieve. Institutionally, the reward systems of most universities are discipline-based. The disciplines often see studies in science, technology, and society as peripheral to their major disciplinary concerns. Therefore, it is difficult to reward scholars who are not based in an interdisciplinary SEEV (usually STS) program that has academic recognition. Intellectually, it can be difficult for SEEV researchers coming out of separate research traditions to appreciate and understand each others' work. Isolation and/or clustering of research communities by theory, method, or topical area - sometimes all three - results. This, in turn, can make peer review difficult and controversial. It can also make it difficult to generalize in cases where generalization may be warranted, and to make connections and build on preceding work.

Where and as it has been possible to generalize, to make connections, and to build on preceding work, progress has been made. For example, some of the early EVIST-supported projects in energy ethics and the management of hazards raised questions about the theoretical justifications for and uses of the concepts of risk-benefit and cost-benefit analysis (Kneese 1977, MacLean 1979, Hume 1983, MacLean 1984, Almeder 1984). A second generation of work followed, examining normative and empirical research agendas in risk- and cost-benefit analysis. These second-generation projects have been interdisciplinary, involving collaborative efforts of economists, sociologists, and philosophers (Baram 1986, Portney 1987, Randall 1987).

An example of the way progress has been made in understanding the implications of cost/risk-benefit analysis is conveniently summarized by Elizabeth Anderson in a recent review in Philosophy and Public Affairs of work that includes results from EVS projects (Nelkin 1981, MacLean 1979, 1980). Anderson astutely summarizes the normative critiques of cost/riskbenefit analysis in so far as this form of analysis must accept certain norms 
of commodity exchanges. She then points out how evidence from Brown and Nelkin's interviews of workers reinforces the critiques by showing that both workers and critiques of cost-benefit analysis weigh the significance of risk in similar ways (Anderson 1988). This convergence of understanding establishes a base for further work, which is already being exploited.

Other researchers studying cost-benefit analysis are examining other forms of decision making that affect policy recommendations. In this regard, the field of agricultural ethics provides some important examples. Costbenefit analysis rests on fundamental assumptions about the importance of utility. Some of the new values typologies that have been developed go beyond concerns for productivity and net gain, to concerns for constraints because of questions of human rights, and for holism or sustainability, because of concerns for the interrelated functioning of natural and social systems (Busch 1983, Busch 1986, Dahlberg 1983).

Thus values identification leads to values analysis, to application, and to policy considerations.

Progress can also be seen in research on engineering ethics. Early projects in this area investigated the norms of individuals and organizations developing and implementing new engineering technologies (Anderson 1976, Babcock 1978, Weil 1978, Unger 1979, Weil 1981, Oakley 1986). As generalizations have emerged, about issues such as responsibility for safety or due care, they are tested empirically as well as normatively. Recent projects by Westin, Bucciarelli, Flores, Whitbeck, and others are examining the implications of engineering and organizational values concerning responsibility for design and the management of complex technologies (Westin 1981, Bucciarelli 1982, Flores 1985, Whitbeck 1987). Thus again empirical research and normative analysis have led to generalization, testing, revision, and application to other fields and to policy considerations.

Many areas in SEEV studies are not as coherent as the areas just discussed. For example, studies of problems associated with research in and the application of RDNA technology have not established or adopted conceptual typologies like those that have facilitated research on engineering ethics. Even when frameworks for understanding evolve, questions about method will remain. Should case studies, interviews, surveys, or other or additional techniques be used? Ought central tendency analysis or outlier analysis be applied to the study of individuals or organizations? What directions for further research are worthwhile? These questions have implications not only for the way research is conducted but for the conclusions that will be reached. There is a dynamic equilibrium between theory and phenomena and dynamic 
interaction between method and conclusions. Thus some ambiguity about the best ways for SEEV research to advance should be expected to continue.

What will it take to continue and to strengthen the progress that has been made? Our conclusions follow, focusing first on intellectual and then institutional considerations.

1. On the intellectual level, SEEV studies need to develop vocabularies and conceptual frameworks of their own. Progress in research requires building on precedents. It depends on the ability of researchers to read and understand each others' work, to recognize the relevance of that work, and to apply findings to their own work. Such broad understanding and cross-disciplinary application is at present difficult. Most SEEV research is based in specific disciplines and uses primarily the tools and vocabularies of those disciplines. This situation will not change until the field of SEEV research has its own vocabularies and conceptual frameworks (Adams, Durbin, and Hollander 1986).

2. Some of the burden for fostering interrelationships and building ties lies with individual researchers. SEEV researchers need to be sensitive to the broad contexts of their work and to make those contexts known when they submit grant requests or publish research articles. Most simply, SEEV researchers need to pay much more attention to discussing how their work will build on or challenge prior related work, with the focus being on SEEV studies and not just disciplinary work.

3. Institutionally, SEEV studies could be helped by more direction from the primary funding agency, NSF-EVS. EVS should develop areas for emphasis within each directorate and across directorates. New guidelines should articulate these priorities clearly. Such direction would alert researchers to important areas of research within SEEV studies and encourage them to relate their own projects to these areas.

4. Finally, SEEV research needs to broaden its basis of support, to include federal agencies other than NSF, foundations, professional societies, and the world of corporate research. ${ }^{10}$ Broader support can increase the amount of SEEV research that can be undertaken. More importantly, it will help ensure that SEEV research does not become tied to prescribed research agendas or particular points of view, thus allowing it to remain free to respond to special opportunities and needs as they present themselves.

It is becoming increasingly apparent that the major problem society will face in the future is not producing more science and technology but learning to live more wisely and justly with the science and technology it has created. SEEV studies have a crucial role to play in confronting and resolving this problem. To assume this role, SEEV researchers must take up the challenge to provide society with balanced, meaningful, and intelligible research results. 


\section{Appendix}

Almeder, Robert F. 1984. RUI: An inquiry and conference about ethical, epistemological and value issues in quantitative risk assessment. \#84-18990.

Anderson, Robert. 1976. An in-depth case study of ethical problems of professional engineers: The BART engineers. \#76-14230.

Babcock, Daniel. 1978. Values and the public work professional. \#78-05729.

Baram. Michael. 1981. Ethical issues in the biological monitoring of occupational health. $\# 81-14738$.

Baram, Michael. 1986. Development of a conceptual framework for evaluating risk assessment as evidence for risk decision-making. \#86-18746.

Bucciarelli, Louis. 1982. Values in engineering design. \#82-114659.

Busch, Lawrence. 1983. Ethics, values, and agricultural research. \#83-17306.

Busch, Lawrence. 1986. Normative issues in the use and maintenance of plant germplasm. \#86-08719.

Chalk, Rosemary. 1983. Openness and secrecy in scientific and technical communication. \#83-09874.

Dahlberg, Kenneth A. 1983. Ethical and value choices in the selection of national agricultural research goals. \#83-09870.

Daniels, Norman. 1987. Distributive justice and consent to risk in the management of hazardous wastes: Do transportable treatment unit technologies offer a technological fix? \#87-11112.

Flores, Albert. 1985. A conference on engineering safety. \#85-18985.

Frankel, Mark. 1987. Science, engineering and ethics: state-of-the-art workshop \#87-18904.

Fritsch, Albert. 1976. Toxic substances and trade secrecy. \#76-17268.

Guttmacher, Sally. 1979. Drugs as medical technology: Ethical issues in treatment of borderline hypertension. \#79-06821.

Haraway, Donna. 1987. Controversies over genetic engineering research for plant protection: An analysis of values, beliefs, and ethical concerns. \#87-10466.

Hume, Jarlath. 1983. Ethics of energy policy: A case study of decision making in Seattle and Tacoma. \#83-17592.

Johnson, Deborah. 1987. Ethical and value issues in research centers. \#87-11341.

Kasperson, Roger. 1977. A study of equity issues in radioactive waste management. \#77-16564.

Kneese, Allen V. 1977. A study of the ethical foundations of benefit-cost analysis techniques. $\# 77-16285$.

Levins, Richard. 1982. Ethical issues in agricultural research in developing countries. \#8204854 .

Lynn, Frances M. 1987. Research, politics and value choices: Making sense of environmental applications of biotechnology. \#87-46868.

MacLean, Douglas. 1979. International ethics and national energy policy. \#79-09907.

MacLean, Douglas. 1980. Risk and Consent: Three Conceptual Models. \#80-20019.

MacLean, Douglas. 1984. Risk and rationality. \#84-17726.

Mitchell, Robert. 1978. Ethical and value dimensions of the nuclear debate, \#78-24813.

Nelkin, Dorothy. 1981. Workers, values, and occupational risk. \#81-112920.

Nelson, James. 1987. An analysis of ethical concerns occasioned by the use of animals in exemplary scientific research: diabetes as a case study. \#87-46867.

Oakley, Stewart. 1986. Values in engineering education and the question of appropriate technology. \#86-08627. 
Orlans, Barbara. 1987. A conference session on new field research guidelines for vertebrate animals. \#87-14611.

Peters, Lois. 1986. University-industry interactions: A study of academic structures and values. \#86-08812.

Portney, Paul. 1987. Assigning discount rates for future life saving: An examination of individuals' preferences. \#87-11083.

Randall, Alan. 1987. Benefit cost analysis and public decisions concerning natural resources and environment: A study in ethics and values. \#87-10153.

Sagoff, Mark. 1986. An analysis of normative and conceptual issues in the regulation of biotechnology in the nation's bays and estuaries. \#86-19104.

Shrader-Frechette, Kristin. 1987. Normative concepts in ecology and their consequences for environmental policy. \#87-19533.

Swazey, Judith. 1987. Professional values and ethical issues in the education of scientists and engineers. \#87-11082.

Sweeting, Linda. 1987. Ethics and the future of chemistry: A symposium. \#87-11086.

Unger, Stephen. 1979. Ethical responsibilities of professional engineering societies. \#79-06980.

Weil, Vivian. 1978. Workshops on ethical issues in engineering. \#78-07276.

Weil, Vivian. 1981. Second national conference on engineering ethics. \#81-26510.

Weil, Vivian. 1984. Ethical implications of trade secrecy, patents, and related property controls for science and technology. \#84-09873.

Westin, Alan. 1981. Ethical dilemmas of scientists and engineers in regulated industries. \#81-07013.

Whitbeck, Caroline. 1987. Engineering innovations, knowledge and responsibility. \#87-46864. Wittemore, Gilbert F., Jr. 1986. Ethical values in the operation of the Federal Radiation Council (1959-1970) \#86-11087.

\section{Notes}

1. The first indication of federal interest in this area for research came in an important notice in 1973, issued jointly by NSF and NEH. NSF issued further announcements in 1976, 1980-1981, and 1986. In 1986, EVIST/EVS was reorganized, tying EVS more closely to the NSF Directorates. For a discussion of the new arrangements in this area, see Hollander 1987.

2. In 1977 Congress included in the conference report on the NSF authorization the statement that EVIST should include "ethical and values issues arising in the context of biological science and clinical medicine" (U.S. Senate 1976). This provision was not included in subsequent reports, allowing the Foundation to focus its EV efforts more exclusively on the nonclinical sciences. Subsequent EVIST/EVS Program Announcements have specifically stipulated that clinically oriented proposals are not encouraged. It is therefore not unexpected that the number of clinically oriented projects has declined along with the number of PIs with MD degrees.

3. It is likely that this distribution will change in the future, as clinical projects drop out and interest in engineering ethics increases.

4. Foundationwide percentages for awards to males and females in 1987 are $90 \%$ male, $10 \%$ female. These average figures mask differences between directorates. For example, awards in biological, behavioral, and social sciences split $85 \%$ male, $15 \%$ female, in engineering the percentages were $96 \%$ male, $4 \%$ female. It should be noted that awards in engineering to women 
are better than the representation of women employed in engineering; this is not true for BBS. These figures come from charts prepared by the director of the Visiting Professorships for Women program at NSF, early in fiscal year 1988.

5. The director of the NSF programs to encourage minority participation in science reports that the latest Foundation effort to encourage minority research is the Minority Centers of Excellence Program, which made two awards to two institutions for a total of $\$ 3$ million in 1987, its first year. The awards went to Howard University and Meharry University in Nashville. Other minority incentive programs include Research Improvement in Minority Institutions, Minority Research Initiation Grants, and Research Assistantships for Minority High School Students.

6. This information was supplied by the office of the NSF Coordinator for Research at Undergraduate Institutions.

7. It should be mentioned again that this article concentrates only on projects funded through EVIST/EVS. It can provide a view of only those components that, for whatever reasons, seem most suited to NSF priority. Thus for instance, it will not include studies of philosophy of technology that might be supported through the History and Philosophy of Science Program at NSF, nor historical or literary studies of medicine that might be funded through NEH or the National Library of Medicine. Nonetheless, we can learn something about both the subject matter and the message suited to some portion of this area by examining these projects.

8. In this section we are discussing only research projects, that is, projects that are designed to add knowledge and increase understanding. We are not discussing projects that have educational goals.

9. The results of the workshop are summarized in Frankel 1988.

10. As examples of the type of broad support that is possible, the following can be noted: the IIT Center for the Study of Ethics in the Professions has been funded by Exxon and the MacArthur Foundation; the programs of Student Pugwash USA are supported by the Sloan and MacArthur Foundations; the Kellogg Foundation supports research on Agriculture and the Humanities; and the Joyce Foundation has undertaken a Biotechnology and Regulation initiative.

\section{References}

Abbott, Andrew. 1983. Professional ethics. American Journal of Sociology 88:855-85.

Adams, Judith, Paul Durbin, and Rachelle Hollander. 1986. Research in STS studies. Bulletin of Science, Technology and Society 6:246-54.

American Association for the Advancement of Science. 1978. EVST resource directory: A directory of programs and courses in the field of ethics and values in science and technology. Document 78-6. Washington, DC: American Association for the Advancement of Science.

Anderson, Elizabeth. 1988. Values, risks, and market norms. Philosophy and Public Affairs 17 (Winter):54-65.

Ashford, Nicholas A. 1983. A framework for examining the effects of industrial funding on academic freedom and the integrity of the university. Science, Technology, \& Human Values 8 (Spring): 16-23.

Blanpied, William A. 1982. Reflections on the first decade. Science, Technology, \& Human Values 7 (Summer):6-7.

Broad, William, and Nicholas Wade. 1982. Betrayers of the truth. New York: Simon \& Schuster. 
Conference on the State of Science, Technology and Society Programs in Western Europe, North America and Australia. 1987. Co-sponsored by the Society for Social Studies of Science and Worcester Polytechnic Institute, November 18-20.

Culliton, Barbara J. 1983. Academe and industry debate partnership. Science 219 (January): 150-51.

Cutcliffe, Stephen H. 1989. The emergence of STS as an academic field. In Ethics and technology, edited by Carl Mitcham, 287-301. Research in Philosophy and Technology, vol. 9. Greenwich, CT: JAI.

Deringer, Dorothy D., and Andrew R. Molnar. 1983. University, industry, federal cooperationA case study. Science, Technology, \& Human Values 8 (Fall):40-5.

Frankel, Mark S. Ed. 1988. Science, engineering and ethics: State-of-the-art and future directions. Washington, DC: American Association for the Advancement of Science, Office of Scientific Freedom and Responsibility.

Fusfield, Warren, 1974. History of the ethical and human value implications of science and technology program. Report prepared for the National Science Foundation, 30 August.

Heitowit. Ezra, Janet Epstein, and Gerald Steinberg. 1976. Science, technology and society: A guide to the field. Ithaca, NY: Cornell University Program on Science, Technology and Society.

Hollander, Rachelle. 1987. Commentary: In a new mode - ethics and values studies at the NSF. Science, Technology, \& Human Values 12 (Spring):59-61.

National Science Board. 1982. University-industry relationships: Myths, realities, and potentials. Fourteenth Annual Report of the National Science Board. Washington, DC: National Science Foundation.

Roy, Rustum, and Joshua Lerner. 1983. The status of STS activities at U. S. universities. Bulletin of Science, Technology and Society 3:417-32.

Staudenmaier, John M. 1985. Technology's storytellers: Reweaving the human fabric. Cambridge, MA: MIT Press.

U.S. Senate. 1976. Conference report, NSF authorization act. Congressional Record, Senate S16591, 24 September.

Zola, Judith C., Jeri A. Sechzer, Joan E. Sieber, and Ann Griffen. 1984. Animal experimentation: Issues for the 1980s. Science, Technology, \& Human Values 9 (Spring):40-50.

Rachelle D. Hollander directs the Program on Studies in Science, Technology and Society at the National Science Foundation, Washington, DC. She is a Fellow of the American Association for the Advancement of Science and a member of the governing board of the National Institue for Engineering Ethics.

Nicholas H. Steneck is Professor of History and Director of the Historical Center for the Health Sciences at the University of Michigan. His major publications are on the history of science and include studies of medieval (Science and Creation, 1975) and contemporary (The Microwave Debate, 1985) subjects. Most recently he has developed an interdisciplinary undergraduate course on professional ethics, which will be published as a textbook. 